\title{
Kinetics and Mechanism of Oxidation of 2-amino-1-Butanol and 3-Amino-1-propanol by Potassium Ferrate
}

\author{
Jinhuan Shan \\ College of Chemistry and Environmental Science, Hebei University \\ Baoding 071002, China \\ E-mail: shanjinhuaner@yahoo.com.cn \\ Jiying Zhang \\ College of Chemistry and Environmental Science, Hebei University \\ Baoding 071002, China \\ Haixia Shen \\ College of Chemistry and Environmental Science, Hebei University \\ Baoding 071002, China \\ Xiaoqian Wang \\ College of Chemistry and Environmental Science, Hebei University \\ Baoding 071002, China
}

\begin{abstract}
The kinetics of oxidation of 2-amino-1-Butanol and 3-Amino-1-propanol by potassium ferrate(VI) in alkaline liquids at a constant ionic strength has been studied spectrophotometrically in the temperature range of 293.2 $\mathrm{K}-313.2 \mathrm{~K}$. The reaction shows first order dependence on potassium ferrate(VI), first order dependence on each reductant. The observed rate constant $\left(k_{\text {obs }}\right)$ decreases with the increase in $\left[\mathrm{OH}^{-}\right]$, the reaction is negative fraction order with respect to $\left[\mathrm{OH}^{-}\right]$. A plausible mechanism is proposed and the rate equations derived from the mechanism can explain all the experimental results. The rate constants of the rate-determining step and the activation parameters are calculated.
\end{abstract}

Keywords: 2-amino-1-Butanol, 3-Amino-1-propanol, Oxidation, Kinetics and mechanism, Potassium ferrate

\section{Introduction}

As early as 1702, ferrate was found by Starl, then in 1841, Fremy first synthesized out potassium ferrate. Ever since a long time ago, people know little about potassium ferrate because it is unstable in water and humid air. In 1948, high purity potassium ferrate crystal was prepared by oxidizing trivalent iron salt in presence of sodium hypochlorite by Schreye and Thompson (Thompson, G. W., Ockerman, L. T., \& Schreye, J. M. 1951). After that, with further research on potassium ferrate, its properties and applications are arousing more and more attention.

Potassium ferrate is a powerful oxidizing agent in the whole $\mathrm{pH}$ range; it is widely used as a water treatment agent (Duan, Y. F., Ding, Y., \& Zhang, Y. Q. 1998; Wu, L. P. 1994; Zhang, J., Shi, Q. L., \& Yang, G. M. 2000) in 1970s. It can remove the phenolic, sulfide and other organic pollutants (Michael, E., Duane, R. C. 1994) which are residual in wastewater, and also can oxidize the cyanide (Waite, T. D., Gray, K. A. 1984) into $\mathrm{NO}_{2^{-}}$, $\mathrm{NO}_{3}$-and $\mathrm{HCO}_{3}$ - which are harmless to environment. Ferrate as a very effective, selective oxidant which can remove effectively $\mathrm{H}_{2} \mathrm{~S}, \mathrm{CH}_{3} \mathrm{SH}_{2}$, and $\mathrm{NH}_{3}$ etc (Virender, K. S., John, T. B., \& Vishwas, N. J. 1998) odor substances in biological sludge. The treated sludge can be used as chemical fertilizer and soil conditioner, it is propitious to waste resource utilization.

Applied prospects of ferrate oxidation are becoming hotspot of research (Stuart, L., Wang, B. H., \& Susanta, G. 1999). Oxidability of ferrate is stronger than potassium permanganate, ozone and chlorine. As a new water 
treatment agent, it has a trend to replace chlorine-atom. In recent years, James Carr etc used potassium ferrate as water treatment agent, while they studied self-decomposition of potassium ferrate in a wide $\mathrm{pH}$ range $(\mathrm{pH}=2.53-9.31)$ (James, Carr. 1985) and the reaction of oxidizing a variety of organic matters (James, 1986). They had proposed rate equation which is applicable to the majority systems. The rate equation includes self-decomposition of potassium ferrate and the reaction of potassium ferrate with the substrate. They also established new methods to deal with kinetic data of such reaction systems (Thompson, G. W., Ockerman, L. T., \& Schreyer, J. M. 1951). However, all studies were not put forward the reaction mechanism to explain the experimental facts.

2-amino-1-Butanol is a mixture of optical isomers which is a colorless liquid with ammonia odor. It is mainly used for preparing emulsifiers, surfactants, resinifyingagent, polishing agent, vulcanization accelerator and pharmaceutical raw materials. It is also absorbance of acid gas for removing sulfureted hydrogen and carbon dioxide. D-structure of this product is also used as raw materials of antimicrobial agents and uterine contraction hemostat. 3-Amino-1-propanol is colorless liquid with hygroscopicity and causticity. It can mixed dissolve with water, ethanol, acetone and chloroform. It is an important organic synthesis intermediates. It can synthesize DL-Panthenol and drugs such as cyclophosphamide and segontin.

In this paper, the kinetics and mechanism of oxidation of 2-amino-1-Butanol and 3-Amino-1-propanol by potassium ferrate were studied in detail.

\section{Experimental}

\subsection{Materials and apparatus}

All the reagents used were of A.R. grade. All solutions were prepared with doubly distilled water. Potassium ferrate $\left(\mathrm{K}_{2} \mathrm{FeO}_{4}\right)$ was prepared by the method of Thompson et al (Thompson, G. W., Ockerman, L. T., \& Schreyer, J. M. 1951). The concentration of $\mathrm{K}_{2} \mathrm{FeO}_{4}$ was derived from its absorption at $507 \mathrm{~nm}\left(\varepsilon=1.15 \times 10^{3} \mathrm{~L} \cdot \mathrm{mol}^{-1} \cdot \mathrm{cm}^{-1}\right)$. The solution of $\mathrm{K}_{2} \mathrm{FeO}_{4}$ was always freshly prepared before use. $\mathrm{KNO}_{3}$ and the $\mathrm{Na}_{2} \mathrm{HPO}_{4}$ buffer solution were used to maintain ionic strength and acidity of the reaction, respectively. Measurements of the kinetics were performed using a TU-1900 spectrophotometer (Beijing, China) fitted with a DC-2010 thermostat $( \pm 0.1 \mathrm{~K}$, Baoding, China).

\subsection{Kinetics measurements}

All kinetics measurements were carried out under pseudo-first order conditions. The oxidant and reductant were both dissolve in buffer solution which contained required concentration of $\mathrm{KNO}_{3}$ and $\mathrm{Na}_{2} \mathrm{HPO}_{4}$. The reaction was initiated by mixing the $\mathrm{Fe}(\mathrm{VI})$ to reductant solution .The reaction process was monitored automatically by recording the concentration decrease of all the $\mathrm{Fe}(\mathrm{VI})$ species with time $(t)$ at $507 \mathrm{~nm}$ with a TU-1900 spectrophotometer. All other species did not absorb significantly at this wavelength.

\subsection{Product analysis}

After completion of the reaction, adding $\mathrm{K}_{3} \mathrm{Fe}(\mathrm{CN})_{6}$ to the solution have non-experimental phenomena, while adding $\mathrm{K}_{4} \mathrm{Fe}(\mathrm{CN})_{6}$ is generated Prussian blue precipitate; by adding 2,2-bipyridyl methanol solution have non-experimental phenomena also. It is prove that the final reduction product of $\mathrm{Fe}(\mathrm{VI})$ is $\mathrm{Fe}(\mathrm{III})$ (Dong, $\mathrm{X}$. W. 1984). After completion of the reaction, the oxidation product was identified as aldehyde alcohols which was precipitated as 2, 4-dinitrophenylhydrazone derivative.

\subsection{Reaction intermediate}

Added 1,10-phenanthroline to reductant solution, then mixed with the $\mathrm{K}_{2} \mathrm{FeO}_{4}$ solution, purple disappeared at the same time orange appeared, indicating that $\mathrm{Fe}(\mathrm{phen})_{3}{ }^{2-}$ have generated in the process of reaction (Dong, $\mathrm{X}$. W. 1984). It is prove that $\mathrm{Fe}(\mathrm{II})$ stage have once appeared in the process of $\mathrm{Fe}(\mathrm{VI})$ reduction to $\mathrm{Fe}(\mathrm{III})$.

\section{Results and discussion}

\subsection{Evaluation of pseudo-first order rate constants}

Under the conditions of [reductant $]_{0}>>[\mathrm{Fe}(\mathrm{VI})]_{0}$, the plots of $\ln \left(A_{\mathrm{t}}-A_{\infty}\right)$ versus time $t$ were straight line, indicating the reaction is first order with respect to the $\mathrm{Fe}(\mathrm{VI})$ complex, where $A_{\mathrm{t}}$ and $A_{\infty}$ are the absorbance at time $t$ and at infinite time, respectively. The pseudo-first-order rate constants $k_{\mathrm{obs}}$ were calculated by the method of least squares $(\mathrm{r} \geq 0.997)$. Generally, to calculate $k_{\mathrm{obs}} 8-10 A_{\mathrm{t}}$ values within there times of the half-lives were used. The $k_{\text {obs }}$ values were the average values of at least there independent experiments, and reproducibility is within $\pm 5 \%$ (Shan, J. H., Qian, J., \& Gao, M. Z. 2004). 


\subsection{Rate dependence on [reductant]}

At fixed [Fe( $\mathrm{VI})],\left[\mathrm{OH}^{-}\right]$, ionic strength $I$, the values of $k_{\mathrm{obs}}$ were determined at different temperatures. The $k_{\mathrm{obs}}$ were found to be increased with the increase of reactant concentration. The plots of $k_{\mathrm{obs}}$ versus [reductant] were linear. For the plots passed through the grid origin (Figure 1 and Figure 2), the reaction was first order with reductant.

\subsection{Rate dependence on $\left[\mathrm{OH}^{-}\right]$}

Under fixed [Fe(VI)], [reductant], ionic strength $I$ and temperature, $k_{\text {obs }}$ values were decreased with an increase of $\left[\mathrm{OH}^{-}\right]$. The order with respect to $\mathrm{OH}^{-}$was found to be negative fractional. The liners of $1 / k_{\text {obs }}$ versus $\left[\mathrm{OH}^{-}\right]$ were done (Figure 3 and Figure 4).

\section{Reaction mechanism}

James Carr (James, Carr. 1986) has given the rate equation as follows: rate $=\mathrm{k}_{1}\left[\mathrm{FeO}_{4}{ }^{2-}\right]+\mathrm{k}_{2}\left[\mathrm{FeO}_{4}{ }^{2-}\right]^{2}+\mathrm{k}$ $\left[\mathrm{FeO}_{4}{ }^{2-}\right][\mathrm{S}]$

where [S] represents substrate concentration. James Carr thinks: the first two terms is contribution of $\mathrm{K}_{2} \mathrm{FeO}_{4}$ self-decomposition rate to the reaction system when there is no substrate. In this article, under the experimental conditions, the self-decomposition rate of $\mathrm{K}_{2} \mathrm{FeO}_{4}$ is far less than oxidation rate of reductant reaction, so we get the rate equation: rate $=\mathrm{k}\left[\mathrm{FeO}_{4}{ }^{2-}\right][\mathrm{R}]$. In essence, the results were consistent with James Carr.

Ferrate(VI) is a dicarboxylic acid(James, Carr. 1985), where:

$$
\begin{aligned}
& \mathrm{H}_{2} \mathrm{FeO}_{4} \rightleftharpoons \mathrm{HFeO}_{4}{ }^{-}+\mathrm{H}^{+} \quad \mathrm{pK}_{\mathrm{a} 1}=3.5 \\
& \mathrm{HFeO}_{4}{ }^{-} \rightleftharpoons \mathrm{H}^{+}+\mathrm{FeO}_{4}{ }^{2-} \quad \mathrm{pK}_{\mathrm{a} 2}=7.8
\end{aligned}
$$

Under the experimental conditions of this paper, $\mathrm{FeO}_{4}{ }^{2-}$ will be partial hydrolysis:

$$
\mathrm{FeO}_{4}{ }^{2-}+\mathrm{H}_{2} \mathrm{O} \rightleftharpoons \mathrm{HFeO}_{4}^{-}+\mathrm{OH}^{-}
$$

Hence:

$$
K_{h}=\frac{\left[\mathrm{HFeO}_{4}^{-}\right]\left[\mathrm{OH}^{-}\right]}{\left[\mathrm{FeO}_{4}{ }^{2-}\right]}=\frac{K_{w}}{K_{a 2}}=6.31 \times 10^{-7}
$$

This experiment is performed at $\mathrm{pH}=10.10$ and 10.42 , then there is

$$
\frac{\left[\mathrm{HFeO}_{4}^{-}\right]}{\left[\mathrm{FeO}_{4}{ }^{2-}\right]}=\frac{K_{h}}{\left[\mathrm{OH}^{-}\right]}=5.01 \times 10^{-3} \text { and } \frac{\left[\mathrm{HFeO}_{4}^{-}\right]}{\left[\mathrm{FeO}_{4}{ }^{2-}\right]}=\frac{K_{h}}{\left[\mathrm{OH}^{-}\right]}=2.40 \times 10^{-3}
$$

Obviously, $\mathrm{HFeO}_{4}^{-}$both have a small percentage in the system. The concentration of $\mathrm{HFeO}_{4}^{-}$is small, but it is very easy to form complex with reductant in the presence of hydrogen atom, and the complex has higher activity. Under the attack of hydroxyl, the complex dissociates into Fe(IV) and product, then $\mathrm{Fe}(\mathrm{IV})$ with another molecule of reductant further react to generate Fe(II) and product. Therefore, reaction is mainly through $\mathrm{HFeO}_{4}^{-}$to realize.

According to discussion, the following reaction mechanism is proposed:

$$
\begin{gathered}
\mathrm{FeO}_{4}{ }^{2-}+\mathrm{H}_{2} \mathrm{O} \stackrel{K_{\mathrm{h}}}{\rightleftharpoons} \mathrm{HFeO}_{4}^{-}+\mathrm{OH}^{-} \\
\mathrm{HFeO}_{4}^{-}+\mathrm{R} \frac{k_{2}}{k_{-2}} \mathrm{X} \\
X+\mathrm{OH}^{-} \stackrel{k_{3}}{\longrightarrow} \mathrm{Fe}(I V)+P(\text { product })
\end{gathered}
$$




$$
\begin{gathered}
F e(I V)+R \stackrel{k 4}{\longrightarrow} F e(I I)+P(\text { product }) \\
\mathrm{Fe}(\mathrm{IV})+\mathrm{Fe}(\mathrm{II}) \stackrel{k_{5}}{\longrightarrow} 2 \mathrm{Fe}(\mathrm{III})
\end{gathered}
$$

Reaction (4) is the rate-determining step, where R stands for reductant. As the rate of the disappearance of $\left[\mathrm{FeO}_{4}{ }^{2-}\right]$ was monitored, the rate of the reaction can be derived as:

$$
\begin{aligned}
& -\frac{\mathrm{d}\left[\mathrm{FeO}_{4}{ }^{2-}\right]}{\mathrm{dt}}=k_{2}\left[\mathrm{HFeO}_{4}^{-}\right][\mathrm{R}]-k_{-2}[\mathrm{X}] \\
& =\frac{k_{2} k_{3}\left[\mathrm{HFeO}_{4}^{-}\right][\mathrm{R}]\left[\mathrm{OH}^{-}\right]}{k_{-2}+k_{3}\left[\mathrm{OH}^{-}\right]}
\end{aligned}
$$

Equation (9) can be obtained from (3):

$$
\left[\mathrm{HFeO}_{4}^{-}\right]=\frac{K_{\mathrm{h}}\left[\mathrm{FeO}_{4}^{2-}\right]}{\left[\mathrm{OH}^{-}\right]}
$$

Substituting equation (9) into (8), we can get the following equation (10):

$$
\begin{aligned}
-\frac{\mathrm{d}\left[\mathrm{FeO}_{4}^{2-}\right]}{\mathrm{dt}} & =\frac{k_{2} k_{3} K_{\mathrm{h}}\left[\mathrm{FeO}_{4}{ }^{2-}\right][\mathrm{R}]}{k_{-2}+k_{3}\left[\mathrm{OH}^{-}\right]}=\frac{k_{2} k_{3} K_{\mathrm{h}}[\mathrm{R}]}{k_{-2}+k_{3}\left[\mathrm{OH}^{-}\right]}\left[\mathrm{FeO}_{4}{ }^{2-}\right] \\
k_{\text {obs }} & =\frac{k_{2} k_{3} K_{\mathrm{h}}[\mathrm{R}]}{k_{-2}+k_{3}\left[\mathrm{OH}^{-}\right]}=\frac{k_{2} k^{\prime} K_{\mathrm{h}}[\mathrm{R}]}{1+k^{\prime}\left[\mathrm{OH}^{-}\right]}
\end{aligned}
$$

in the equation $k^{\prime}=k_{3} / k_{-2}$

$$
\frac{1}{k_{\mathrm{obs}}}=\frac{1+k^{\prime}\left[\mathrm{OH}^{-}\right]}{k_{2} k^{\prime} K_{\mathrm{h}}[\mathrm{R}]}=\frac{1}{k_{2} k^{\prime} K_{\mathrm{h}}[\mathrm{R}]}+\frac{\left[\mathrm{OH}^{-}\right]}{k_{2} K_{\mathrm{h}}[\mathrm{R}]}
$$

Equation (10) suggests that the reaction should be first order with respect to $\mathrm{Fe}(\mathrm{VI})$; equation (11) suggests that the order with respect to $\mathrm{R}$ is unity. The plot of $1 / k_{\text {obs }}$ versus $\left[\mathrm{OH}^{-}\right]$derived from equation (12) at constant $[\mathrm{R}]$ is linear with positive intercept. These are consistent with the experimental phenomena.

Meanwhile, the plots of $1 / k_{\text {obs }}$ versus $\left[\mathrm{OH}^{-}\right]$were liner at different temperatures. From their slopes and equation (12), the rate-determining step constants $\left(k_{2}\right)$ were evaluated, and the activation parameters date were obtained (Table 1) (Shan, J. H., Liu, T. Y. 1994).

It is noteworthy that according to equation (12) and Figure $(3,4)$, we can get the values of $k^{\prime}$ under corresponding temperature. And then, substituting the $k^{\prime}, k_{2}$ and $\left[\mathrm{OH}^{-}\right]$into equation (11), we can calculate the rate constants in corresponding $[R]$, we found that the calculated value is very close to the experimental value (Table 2 and Table 3). This also illustrates the equation (12) is correct and the reaction mechanism we supposed is reasonable.

\section{Conclusion}

Based on the above discussion and results, we can know that the reaction of potassium ferrate with 2-amino-1-Butanol and 3-Amino-1-propanol both are completed by double-electron transfer and we also observed the rate of the rate-determining step of 3-Amino-1-propanol is quicker than that of 2-amino-1-Butanol, the rate constants of the rate determining step for 3-Amino-1-propanol are larger than those for 2-amino-1-Butanol. The effect of $\left[\mathrm{OH}^{-}\right]$and the activation parameters are all in support of the mechanism and consistent with experimental phenomena.

In the reaction system, we also observe that the activation energy of experiment is very small, but the entropy of 
activation has a big negative value. So according to the literature (Fu, X. C., Shen, W. X., \& Yao, T. Y. 1990), it is reasonable that the reaction rate is not too fast.

\section{References}

Dong, X. W. (1984). Detection of all kinds of Ions in the Chemical Method, Bei Jing: Beijing Normal University Press, 94.

Duan, Y. F., Ding, Y., \& Zhang, Y. Q. (1998). Preparation of potassium ferrateVI and Application in water. Modern Chemical Industry, 3, 17.

Fu, X. C., Shen, W. X., \& Yao, T. Y. (1990). Physical Chemistry, Beijing: Higher Education Press, 812.

James, Carr. (1985). Proceedings of the Conference on Water Chlorination and Chem Environ. Impact Health Eff, 1285.

James, Carr. (1986). The kinetics of Oxidation of Simple Aliphatic Sulphur Compounds by Potassium Ferrate. Transition Met. Chem, 11, 116.

Michael, E., Duane, R. C. (1994). Removal of radionuclide in waste water utilizing potassium ferrate(VI). Water Environment Research, 66(2), 107.

Shan, J. H., Liu, T. Y. (1994). Kinetics and mechanism of substitution reactions of bis(N,N-diethyldithiocarbamato)alkylxanthatocobalt(III) with dipropylamine and di-n-butylamine in methanol. Acta Chim. Sinica, 52, 1140.

Shan, J. H., Qian, J., \& Gao, M. Z. (2004). Kinetics and Mechanism of Oxidation of n-Propanolamine by Dihydroxydiperiodatonickelate(VI) in Alkaline Medium. Turk J Chem, 28, 9-15.

Stuart, L., Wang, B. H., \& Susanta, G. (1999). Energetic Iron(VI) Chemistry: The Super-Iron Battery. Science, 285(3), 1039-1042.

Thompson, G. W., Ockerman, L. T., \& Schreye, J. M. (1951). Preparation and purification of potassium ferrate(VI). J AM Chem Soc, 73, 1379.

Thompson, G. W., Ockerman, L. T., \& Schreyer, J. M. (1951). Preparation and Purification of Potassium Ferrate(VI). J Am Chem Soc, 73, 1379-1381.

Virender, K. S., John, T. B., \& Vishwas, N. J. (1998). Oxidation of ammonia by ferrate(VI). Environ Sci, 33(4), 635 .

Waite, T. D., Gray, K. A. (1984). Utilizing ferrate(VI) iron oxidation and coagulation of waste water effluent study. Environ Sci, 23, 407.

Wu, L. P. (1994). A new efficient Water Treatment- Potassium Ferrate(VI). Henan Chemical Industry, 2, 22.

Zhang, J., Shi, Q. L., \& Yang, G. M. (2000). Synthesis of potassium ferrateVI and Application in water. Environmental Protection of Chemical Industry, 20(1), 44.

Table 1. Rate constants $\left(k_{2}\right)$ and Thermodynamic activation parameters of the rate-determining step

\begin{tabular}{|c|c|c|c|c|c|c|}
\hline \multicolumn{2}{|c|}{$\mathrm{T}(\mathrm{K})$} & 293.2 & 298.2 & 303.2 & 308.2 & 313.2 \\
\hline \multirow{2}{*}{$k_{2} / \mathrm{mol}^{-1} \cdot \mathrm{L} \cdot \mathrm{s}^{-1}$} & 2-amino-1-Butanol & 47.60 & 64.12 & 85.95 & 111.64 & \\
\cline { 2 - 7 } & 3-Amino-1-propanol & & 308.52 & 351.47 & 410.06 & 463.33 \\
\hline \multirow{2}{*}{$\begin{array}{c}\text { Thermodynamic } \\
\text { activation parameters }\end{array}$} & 2-amino-1-Butanol & $E_{\mathrm{a}}=42.98 \mathrm{~kJ} \cdot \mathrm{mol}^{-1}, \Delta H^{\ddagger}=40.50 \mathrm{~kJ} \cdot \mathrm{mol}^{-1}, \Delta S^{\ddagger}=-74.54 \mathrm{~J} \cdot \mathrm{K}^{-1} \cdot \mathrm{mol}^{-1}$ \\
\cline { 2 - 7 } & 3-Amino-1-propanol & $E_{\mathrm{a}}=21.33 \mathrm{~kJ} \cdot \mathrm{mol}^{-1}, \Delta H^{\ddagger}=18.85 \mathrm{~kJ} \cdot \mathrm{mol}^{-1}, \Delta S^{\ddagger}=-134.02 \mathrm{~J} \cdot \mathrm{K}^{-1} \cdot \mathrm{mol}^{-1}$ \\
\hline
\end{tabular}

The plots of lnk vs. 1/T have following intercept (a) slope (b) and relative coefficient (r). 2-amino-1-Butanol: $\mathrm{a}=$ $21.44 \mathrm{~b}=-5152.72 \mathrm{r}=0.9999,3$-Amino-1-propanol: $\mathrm{a}=14.34 \mathrm{~b}=-2566.86 \mathrm{r}=0.9992$ 
Table 2. The values of $k_{\text {obs }}$ experimental and calculated at different temperatures

\begin{tabular}{llllllllllll}
\multicolumn{8}{c}{$\left(\left[\mathrm{OH}^{-}\right]=1.26 \times 10^{-4} \mathrm{~mol} \cdot \mathrm{L}^{-1} \mathrm{R}=2\right.$-amino-1-Butanol $)$} \\
\hline
\end{tabular}

Table 3. The values of $k_{\text {obs }}$ experimental and calculated at different temperatures

\begin{tabular}{ccccccccccccc}
\multicolumn{10}{c}{$\left(\left[\mathrm{OH}^{-}\right]=2.63 \times 10^{-4} \mathrm{~mol} \cdot \mathrm{L}^{-1} \mathrm{R}=3-\right.$ Amino-1-propanol $)$} \\
\hline
\end{tabular}

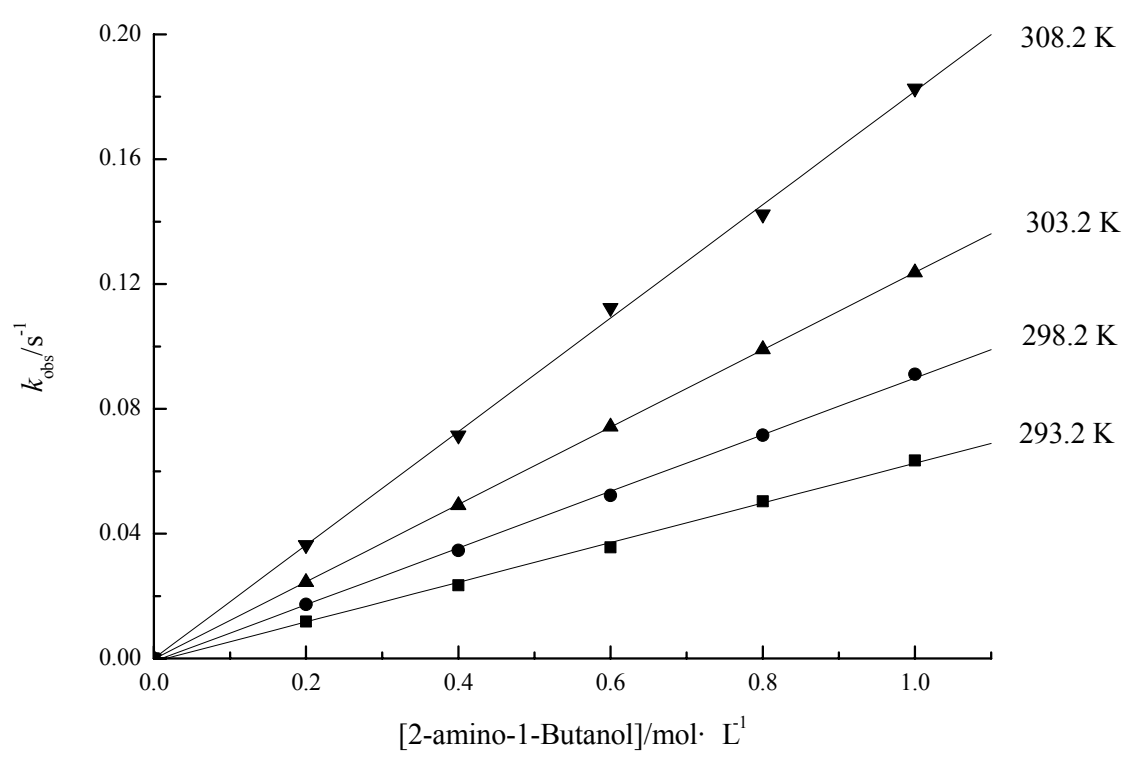

Figure 1. Plots of $k_{\mathrm{obs}}$ versus [2-amino-1-Butanol] at different temperatures $(\mathrm{r} \geq 0.999)$ $[\mathrm{Fe}(\mathrm{VI})]=1.83 \times 10^{-4} \mathrm{~mol} \cdot \mathrm{L}^{-1},[\mathrm{OH}]=1.26 \times 10^{-4} \mathrm{~mol} \cdot \mathrm{L}^{-1}, I=1.00 \mathrm{~mol} \cdot \mathrm{L}^{-1}$ 


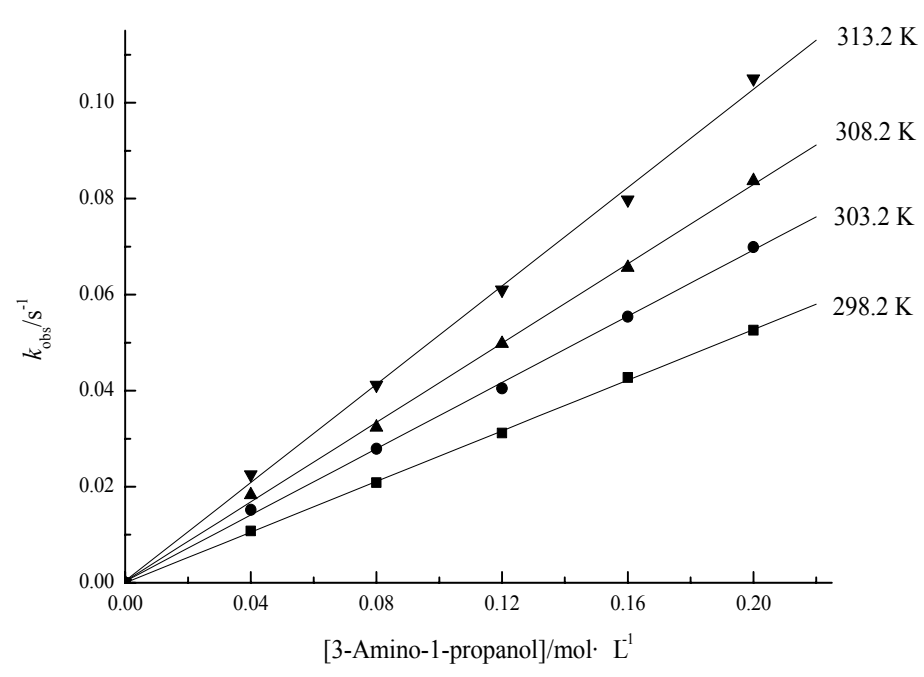

Figure 2. Plots of $k_{\mathrm{obs}}$ versus [3-Amino-1-propanol] at different temperatures $(\mathrm{r} \geq 0.999)$ $[\mathrm{Fe}(\mathrm{VI})]=1.74 \times 10^{-4} \mathrm{~mol} \cdot \mathrm{L}^{-1},\left[\mathrm{OH}^{-}\right]=2.63 \times 10^{-4} \mathrm{~mol} \cdot \mathrm{L}^{-1}, I=1.00 \mathrm{~mol} \cdot \mathrm{L}^{-1}$

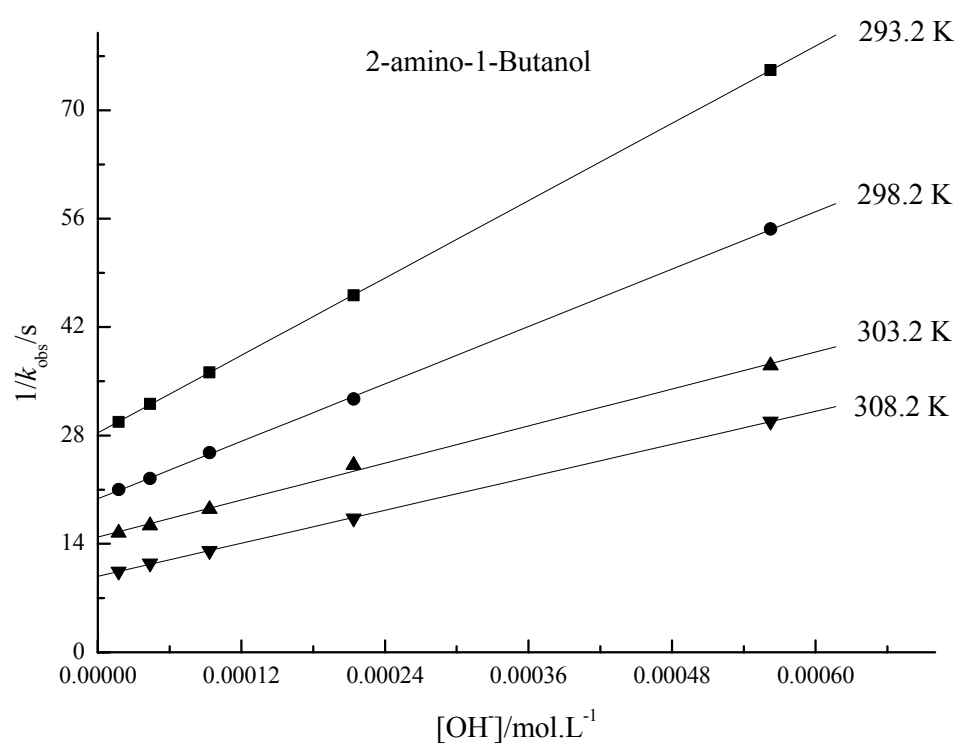

Figure 3. Plots of $1 / k_{\mathrm{obs}}$ versus $\left[\mathrm{OH}^{-}\right]$at different temperatures $(\mathrm{r} \geq 0.999)$ $[\mathrm{Fe}(\mathrm{VI})]=1.57 \times 10^{-4} \mathrm{~mol} \cdot \mathrm{L}^{-1},[2$-amino-1-Butanol $]=0.40 \mathrm{~mol} \cdot \mathrm{L}^{-1}, I=1.00 \mathrm{~mol} \cdot \mathrm{L}^{-1}$ 


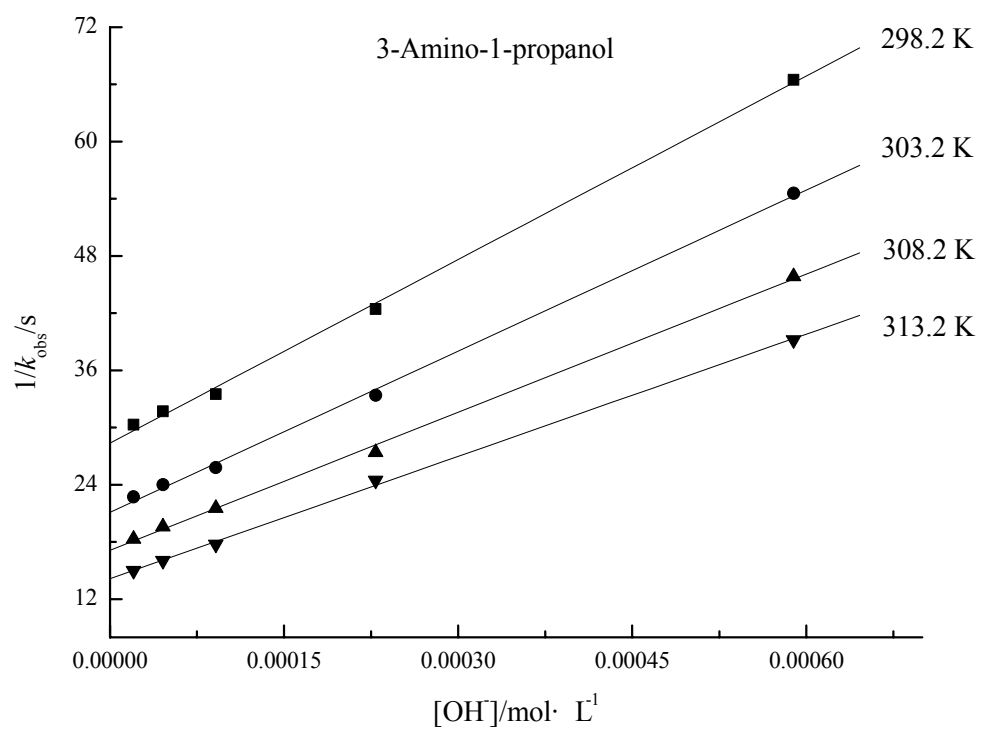

Figure 4. Plots of $1 / k_{\text {obs }}$ versus $\left[\mathrm{OH}^{-}\right]$at different temperatures $(\mathrm{r} \geq 0.999)$ $[\mathrm{Fe}(\mathrm{VI})]=1.74 \times 10^{-4} \mathrm{~mol} \cdot \mathrm{L}^{-1},[3-$ Amino-1-propanol $]=0.08 \mathrm{~mol} \cdot \mathrm{L}^{-1}, I=1.00 \mathrm{~mol} \cdot \mathrm{L}^{-1}$ 